\title{
Peripheral Blood Gene Expression and IgG Glycosylation Profiles as Markers of Tocilizumab Treatment in Rheumatoid Arthritis
}

\author{
BERTALAN MESKO, SZILARD POLISKA, SZILVIA SZAMOSI, ZOLTAN SZEKANECZ, JANOS PODANI, \\ CSABA VARADI, ANDRAS GUTTMAN, and LASZLO NAGY
}

ABSTRACT. Objective. Tocilizumab, a humanized anti-interleukin-6 receptor monoclonal antibody, has recently been approved as a biological therapy for rheumatoid arthritis (RA) and other diseases. It is not known if there are characteristic changes in gene expression and immunoglobulin $\mathrm{G}$ glycosylation during therapy or in response to treatment.

Methods. Global gene expression profiles from peripheral blood mononuclear cells of 13 patients with RA and active disease at Week 0 (baseline) and Week 4 following treatment were obtained together with clinical measures, serum cytokine levels using ELISA, and the degree of galactosylation of the $\operatorname{IgG}$ $\mathrm{N}$-glycan chains. Gene sets separating responders and nonresponders were tested using canonical variates analysis. This approach also revealed important gene groups and pathways that differentiate responders from nonresponders.

Results. Fifty-nine genes showed significant differences between baseline and Week 4 and thus correlated with treatment. Significantly, 4 genes determined responders after correction for multiple testing. Ten of the 12 genes with the most significant changes were validated using real-time quantitative polymerase chain reaction. An increase in the terminal galactose content of N-linked glycans of IgG was observed in responders versus nonresponders, as well as in treated samples versus samples obtained at baseline.

Conclusion. As a preliminary report, gene expression changes as a result of tocilizumab therapy in RA were examined, and gene sets discriminating between responders and nonresponders were found and validated. A significant increase in the degree of galactosylation of IgG N-glycans in patients with RA treated with tocilizumab was documented. (First Release April 1 2012; J Rheumatol 2012;39:916-28; doi:10.3899/jrheum.110961)

\section{Key Indexing Terms: \\ TOCILIZUMAB DRUG RESPONSE}

GENE EXPRESSION
IgG GLYCOSYLATION ANTI-INTERLEUKIN-6 RECEPTOR
From the Department of Biochemistry and Molecular Biology, Apoptosis and Genomics Research Group, Hungarian Academy of Sciences; Research Center for Molecular Medicine, Medical and Health Sciences Center, University of Debrecen; Clinical Genomics Center, Medical and Health Sciences Center, University of Debrecen; Department of Rheumatology, Institute of Medicine, Medical and Health Sciences Center, University of Debrecen, Debrecen; and Biological Institute, Eötvös University, Budapest, Hungary.

Dr. Nagy is an International Scholar of Howard Hughes Medical Institute and holds a Wellcome Trust Senior Research Fellowship in Biomedical Sciences. He is supported by grants from the Hungarian Science Research Fund (OTKA NK72730), the Hungarian Ministry of Health (ETT 294-07), MOLMEDREX (FP7-REGPOT-2008-1. \#229920), and TAMOP-4.2.2/08/2, and TAMOP-4.2.1/B-09/1 KONV-2010-0007 implemented through the New Hungary Development Plan co-financed by the European Social Fund and the European Regional Development Fund.

B. Mesko, MD, Department of Biochemistry and Molecular Biology; S. Poliska, PhD, Department of Biochemistry and Molecular Biology and Research Center for Molecular Medicine, Medical and Health Sciences Center, University of Debrecen; S. Szamosi, MD; Z. Szekanecz, MD, PhD, Department of Rheumatology, Institute of Medicine, Medical and Health Sciences Center, University of Debrecen; J. Podani, PhD, Biological Institute, Eötvös University; C. Varadi, BSc; A. Guttman, PhD, Horváth Laboratory of Bioseparation Sciences, Medical and Health Sciences Center, University of Debrecen; L. Nagy, MD, PhD, Department of Biochemistry and Molecular Biology and Research Center for Molecular Medicine, Medical and Health Sciences Center, University of Debrecen. Address correspondence to Dr. L. Nagy.E-mail:nagyl@med.unideb.hu Accepted for publication December 14, 2011.
Biological therapies brought a new era in the treatment of rheumatoid arthritis (RA) and other chronic inflammatory diseases. Because their use is expensive, identification of markers or establishment of scoring systems allowing prediction of the outcome of treatment and/or disease progression would be highly desirable.

Besides the many tumor necrosis factor- $\alpha$ (TNF) inhibitors ${ }^{1}$, other emerging biotherapies such as inhibitors of the interleukin 1 (IL-1) or IL-6 pathways have also been in focus recently.

IL-6 can activate cells through binding to membrane-bound (IL-6R) and soluble receptors (sIL-6R), which has been found to play a key role in acute and chronic inflammation; joint destruction, pannus development, and increased bone resorption ${ }^{2}$; and inflammatory cell migration ${ }^{3}$. As many of the articular and systematic manifestations could be explained by the effect of IL-6, the inhibition of IL-6R rapidly became a validated therapeutic target in RA.

Tocilizumab, a humanized anti-IL-6R monoclonal antibody blocking IL-6-mediated signal transduction, in combination with methotrexate (MTX) is approved as a biological therapy for moderate to severe RA in adult patients with inadequate response to prior disease-modifying antirheumatic

Personal non-commercial use only. The Journal of Rheumatology Copyright @ 2012 . All rights reserved. 
drugs (DMARD) or TNF inhibitors ${ }^{4}$ or those who do not tolerate that therapy. In such cases tocilizumab causes a significant reduction in disease activity ${ }^{5,6}$.

There are an increasing number of gene expression studies focusing on the pathomechanism of RA using either peripheral blood mononuclear cells $(\mathrm{PBMC})^{7}$ or synovial tissue ${ }^{8}$. As PBMC are easy to access and analyze and are considered key cells of inflammation, it is particularly intriguing to assess whether predicting responsiveness to biological therapies is possible by the combination of PBMC gene expression patterns and clinical measures. This approach has been proven successful in other diseases such as breast cancer ${ }^{9}$.

We extended this approach to patients treated with tocilizumab and performed global gene expression profiling and scoring of clinical measures using canonical variates analysis (CVA) to identify gene sets that can differentiate responders from nonresponders.

$\mathrm{N}$-glycosylation of human immunoglobulins, especially IgG1, plays a critical role in the bioactivity of this group of important proteins; and in patients with RA a decrease in terminal galactose content of the N-linked glycans at the conserved Fc region (Asn 297) glycosylation site of IgG occurs as compared to a corresponding age-matched control population ${ }^{10}$. Interestingly, infliximab, a chimeric monoclonal antibody that binds soluble TNF- $\alpha$, reducing its biological activity and inflammation, can reduce the concentration of agalactosyl (G0) glycan of IgG1 in patients with active RA who clinically improved according to the American College of Rheumatology (ACR) criteria following the infliximab/MTX treatment ${ }^{11}$. It is particularly interesting to determine whether other biologic therapies such as tocilizumab can produce the same effect. This and the transcriptomics data obtained on galactosyl transferase expression and its effects on response to treatment prompted us to investigate changes in the relative amount of agalactosyl glycan of IgG1 in RA.

\section{MATERIALS AND METHODS}

Patients. The Research Ethics Committee of University of Debrecen Medical and Health Science Center approved the clinical protocol and the study, which was in compliance with the Helsinki Declaration. Signed informed consent was obtained from all individuals who provided blood samples.

Thirteen white patients ( 9 women, 4 men) who met the ACR criteria for RA were included in the study; all had active disease at the time of blood draw. Two additional patients were excluded later in the study due to allergic reactions or elevated liver enzyme levels. After subjects fasted for $12 \mathrm{~h}$ overnight, all blood samples were obtained locally between 8:00 AM and 9:00 AM before the first administration of tocilizumab at Week 0 (baseline) and the second at Week 4 , and were processed within 1 hour after sample collection.

Details of medications, which remained unchanged during the study, and comorbidity are shown in Tables 1 and 2. Comedication was given after blood was taken.

Clinical measures including Disease Activity Score (DAS) were assessed at the time of the first tocilizumab infusion (baseline), at the second infusion (Week 4), and at Week 14 when remission was determined based on national protocols using ACR criteria. Dosage of tocilizumab was $8 \mathrm{mg} / \mathrm{kg}$ body weight per infusion.

The inclusion criteria in our study were (1) fulfillment of the 1987 American Rheumatism Association criteria; (2) receiving concomitant MTX treatment of maximum $20 \mathrm{mg} / \mathrm{wk}$; (3) age between 30 and 60 years; (4) failure to respond to at least 2 DMARD; (5) active disease defined as having DAS evaluated in 28 joints (DAS28) $>3.2$; (6) having stable MTX, prednisolone, and nonsteroidal antiinflammatory drug doses during the previous 4 weeks before inclusion in the study; and (7) having discontinued previous DMARD at least 4 weeks prior to inclusion. Exclusion criteria were (1) pregnancy or breastfeeding; (2) current or recent malignancies; (3) active infectious disease; or (4) history of acute inflammatory joint disease of a different origin. All patients were TNF-blocking therapy-naive.

$P B M C$ and RNA isolation. Venous peripheral blood samples were collected $(10 \mathrm{ml})$ in vacuum collection tubes containing EDTA (BD Vacutainer K2EDTA; Becton-Dickinson, Franklin Lakes, NJ, USA) and $10 \mathrm{ml}$ in native tubes for the extraction of serum. PBMC were separated by Ficoll gradient centrifugation. Total RNA was extracted from PBMC using Trizol reagent (Invitrogen, Carlsbad, CA, USA), according to the manufacturer's protocol, on the day of blood sampling. RNA quality was checked on Agilent Bioanalyser 2100 (Agilent Technologies, Palo Alto, CA, USA), all samples had a $28 \mathrm{~S} / 18 \mathrm{~S}$ ratio between 1.5 and 2.0 and the RNA integrity number was between 9 and 10. Quantity was determined by NanoDrop.

Microarray analysis. Affymetrix GeneChip Human Gene 1.0 ST array was used to analyze global expression pattern of 28,869 well annotated genes. Ambion WT Expression Kit (Applied Biosystems, Foster City, CA, USA) and GeneChip WT Terminal Labeling and Control Kit (Affymetrix, Santa Clara, CA, USA) were used for amplifying and labeling $250 \mathrm{ng}$ of RNA samples. Samples were hybridized at $45^{\circ} \mathrm{C}$ for $16 \mathrm{~h}$, and then standard washing protocol was performed using GeneChip Fluidics Station 450, and arrays were scanned on GeneChip Scanner 7G (Affymetrix). CEL files of microarrays were uploaded to the Gene Expression Omnibus (GSE25160).

Univariate data analysis. Microarray data (Gene Expression Omnibus accession number: GSE25160) were analyzed with Genespring GX10 (Agilent Biotechnologies). Affymetrix data files were imported using the Robust Multi-array Analysis algorithm, and median normalization was performed. Regarding the baseline versus Week 4 comparison, 26 samples (13 samples at baseline and 13 at Week 4) were used, and $20 \%$ of probe sets with the lowest expression levels were filtered out in the first step (5733 probe sets filtered out). Then the list of 23,136 probe sets was filtered by fold change (1.2-fold cutoff), and statistical analysis was performed using paired Mann-Whitney U test with Benjamini-Hochberg multiple-testing correction.

Regarding the responder versus nonresponder comparison, 13 samples (from baseline) were used; $20 \%$ of probe sets with the lowest expression levels were filtered out in the first step (5679 probe sets). Then the list of 23,190 probe sets was filtered by fold change (1.2-fold cutoff) and statistical analysis was performed using unpaired t test with Benjamini-Hochberg correction for multiple testing.

Functional categorization of genes was performed with Panther Classification System (http://www.pantherdb.org/).

Validation by RT-QPCR. Real-time quantitative polymerase chain reaction (RT-QPCR) was performed to validate a subset of differently expressed transcripts identified by microarray analysis. Individual gene expression assays (Applied Biosystems) of 12 genes selected for validation were used. Reactions were performed in an ABI Prism HT 7900 machine (Applied Biosystems) in triplicate, and all samples $(n=26)$ were included in the validation set. Relative gene expression levels were calculated by comparative $\mathrm{Ct}$ method that results in normalizing to GAPDH expression for each sample. Unpaired and paired $t$ tests were used for statistical analysis $(\mathrm{p}<0.05$ was considered significant).

ELISA. Concentrations of IL-6, IL-1B, and IL-8 in serum were determined with an ELISA kit (Amersham, UK), and the results were given in $\mathrm{pg} / \mathrm{ml}$ by the Regional Immunology Laboratory, Third Department of Internal Medicine, Medical and Health Science Centre, University of Debrecen.

Measuring decrease in degree of galactosylation of $\operatorname{Ig} G \mathrm{~N}$-glycans. IgG was isolated from 9 of the 13 samples from patients with RA using protein A affinity pulldown. The $\mathrm{N}$-glycans were released by peptide- $\mathrm{N}$-glycanase $\mathrm{F}$ (PNGase F). The released glycans were then fluorescently labeled with Personal non-commercial use only. The Journal of Rheumatology Copyright () 2012. All rights reserved. 
Table 1A. Patient measures.

\begin{tabular}{|c|c|c|c|c|c|c|c|c|c|c|c|c|c|}
\hline \multirow[b]{2}{*}{ Characteristic } & \multirow[b]{2}{*}{3} & \multirow[b]{2}{*}{6} & \multirow[b]{2}{*}{10} & \multirow[b]{2}{*}{4} & \multicolumn{3}{|c|}{ Patient } & \multirow[b]{2}{*}{9} & \multirow[b]{2}{*}{11} & \multirow[b]{2}{*}{2} & \multirow[b]{2}{*}{12} & \multirow[b]{2}{*}{13} & \multirow[b]{2}{*}{1} \\
\hline & & & & & 5 & 7 & 8 & & & & & & \\
\hline Response at Week 14 & $\mathrm{R}$ & $\mathrm{R}$ & $\mathrm{R}$ & $\mathrm{R}$ & $\mathrm{R}$ & $\mathrm{R}$ & $\mathrm{R}$ & $\mathrm{R}$ & $\mathrm{R}$ & NR & NR & NR & NR \\
\hline Gender & $\mathrm{F}$ & $\mathrm{F}$ & $\mathrm{F}$ & $\mathrm{F}$ & $\mathrm{F}$ & $\mathrm{F}$ & M & $\mathrm{F}$ & $\mathrm{F}$ & M & M & M & $\mathrm{F}$ \\
\hline Duration of disease, mo & 36 & 480 & 204 & 24 & 192 & 24 & 60 & 156 & 96 & 48 & 156 & 180 & 300 \\
\hline \multicolumn{14}{|l|}{ DAS28 at Week } \\
\hline 0 & 5.36 & 5.06 & 5.2 & 4.36 & 5.07 & 5.21 & 5.15 & 6 & 5.82 & 7 & 4.62 & 5.21 & 6.42 \\
\hline 4 & 3.33 & 3.62 & 2.39 & 2.53 & 6 & 3.75 & 3.86 & 4.88 & 2.8 & 6.21 & 3.1 & 1.21 & 3.98 \\
\hline 14 & 0.16 & 1.21 & 1.64 & 2.54 & 2.68 & 3.2 & 3.82 & 3.21 & 1.97 & 4 & 2.72 & 3.37 & 5.82 \\
\hline \multicolumn{14}{|l|}{ HAQ at Week } \\
\hline 0 & 1.375 & 2.25 & 0.75 & 1.375 & 2.62 & 2.125 & 1 & 2.75 & 2.25 & 1.75 & 1.75 & 1.875 & 0.75 \\
\hline \multicolumn{14}{|l|}{ CRP at Week } \\
\hline 4 & 0.5 & 2.51 & 0.52 & 1.5 & 4 & 0.6 & 22.81 & 8.7 & 0.5 & 45.4 & 161.81 & 0.5 & 3.87 \\
\hline 14 & 0.5 & 0.54 & 0.9 & 0.5 & 0.5 & 0.5 & 16.7 & 5.4 & 0.5 & 129.56 & 59.6 & 0.5 & 3.2 \\
\hline \multicolumn{14}{|l|}{ ESR at Week } \\
\hline 0 & 8 & 22 & 22 & 14 & 40 & 10 & 50 & 40 & 50 & 23 & 90 & 10 & 38 \\
\hline 4 & 2 & 8 & 2 & 5 & 11 & 6 & 19 & 28 & 2 & 33 & 76 & 2 & 6 \\
\hline 14 & 1 & 4 & 4 & 7 & 9 & 3 & 18 & 4 & 2 & 80 & 20 & 8 & 28 \\
\hline Previous DMARD & 2 & 3 & 3 & 5 & 4 & 2 & 3 & 3 & 5 & 4 & 6 & 2 & 3 \\
\hline MTX dose, mg/wk & 15 & 15 & 7.5 & 20 & 10 & 15 & 12.5 & 20 & 15 & 7.5 & 15 & 20 & 10 \\
\hline Prednisone use, mg/wk & 0 & 0 & 0 & 0 & 0 & 0 & 0 & 0 & 8 & 4 & 0 & 4 & 0 \\
\hline Comorbidity & None & HT & None & None & None & HT & None & HT & $\mathrm{CD}$ & None & None & None & HT \\
\hline
\end{tabular}

Data are shown as mean \pm SD regarding the total group; and mean \pm range in both responders and nonresponders. ACR: American College of Rheumatology criteria; R: responder, NR: nonresponder, Brinkman index: no. cigarettes smoked per day $\times$ smoking years, calculated by summing separate Brinkman indices in 3 age periods; DAS28: Disease Activity Score; HAQ: Health Assessment Questionnaire; CRP: C-reactive protein; ESR: erythrocyte sedimentation rate; DMARD: disease-modifying antirheumatic drug; MTX: methotrexate, HT: hypertension, CD: Crohn disease.

aminopyrene-trisulfonate and analyzed by capillary gel electrophoresis with laser-induced fluorescence detection. The aim of this part of the study was to investigate the changes in the relative amount of agalactosylated (G0) glycans before and after the treatment.

Protein A affinity. Protein A is a surface protein originally found in the cell wall of the bacteria Staphylococcus aureus with the ability to bind immunoglobulins via their Fc region. In our experiments, Phytip (PhyNexus, San Jose, CA, USA) columns were used with $20 \mu$ l protein A resin bed volume. In the first step $100 \mu 1$ serum was dissolved in $200 \mu 1$ Phynexus protein A capture buffer ( $\left.50 \mathrm{mM} \mathrm{NaH}_{2} \mathrm{PO}_{4}, 0.7 \mathrm{M} \mathrm{NaCl}, \mathrm{pH} 7.4\right)$. The IgG molecules were captured by passing the sample through the resin bed ( 4 cycles at flow rate $100 \mu 1 / \mathrm{min}$ ). During purification steps $500 \mu 1$ Wash Buffer I (50 mM $\mathrm{NaH}_{2} \mathrm{PO}_{4}, 0.7 \mathrm{M} \mathrm{NaCl}, \mathrm{pH}$ 7.4) was rinsed through the resin bed ( 1 cycle at flow rate $250 \mu \mathrm{l} / \mathrm{min}$ ) followed by a second wash step with $1000 \mu \mathrm{l}$ Wash Buffer II $(150 \mathrm{mM} \mathrm{NaCl})$ rinsed through the resin bed (1 cycle at flow rate $250 \mu \mathrm{l} / \mathrm{min}$ ). After washing steps, captured $\mathrm{IgG}$ was recovered from the protein A column by rinsing with $150 \mu 1$ enrichment buffer $\left(200 \mathrm{mM} \mathrm{NaH}_{2} \mathrm{PO}_{4}\right.$, $140 \mathrm{mM} \mathrm{NaCl}, \mathrm{pH} 2.5 ; 4$ cycles at flow rate $100 \mu 1 / \mathrm{min}$ ). Since the $\mathrm{pH}$ of the elution buffer was 2.5 , a buffer exchange was necessary using $10 \mathrm{kDa}$ Microcon spin filters (Millipore, Billerica, MA, USA).

PNGase F digestion. PNGase F [peptide-N4-(acetyl-ß-glucosaminyl)-asparagine amidase] cleaves asparagine-linked glycan structures from glycoproteins. While PNGase F deaminates the asparagine to aspartic acid, it leaves the released oligosaccharide intact.

First, the glycoproteins were denaturated by addition of $5 \mu 1$ denaturation buffer (New England Biolabs, Ipswich, MA, USA) at $98^{\circ} \mathrm{C}$ for $10 \mathrm{~min}$. After denaturation, $35 \mu 1 \mathrm{HPLC}$ water, $12.5 \mu 1 \mathrm{G} 7$ buffer, $12.5 \mu 1 \mathrm{NP} 40$, and $10 \mu 1$ PNGase F (Prozyme, Hayward, CA, USA) were added to the solution and digested overnight at $37^{\circ} \mathrm{C}$.

APTS labeling. 8-aminopyrene-1,3,6-trisulfonic acid (Beckman Coulter, Brea, CA, USA) was used as perfect fluorescent dye for all capillary gel electrophoresis (CGE) analysis. The glycans were labeled via reductive amination by the addition of $1 \mu 10.2 \mathrm{M}$ APTS in $15 \%$ acetic acid and $1 \mu 11 \mathrm{M}$ $\mathrm{NaBH}_{3} \mathrm{CN}$. The labeling reaction was incubated overnight at $37^{\circ} \mathrm{C}$.

CGE-laser induced fluorescence analysis. For CGE analysis of the labeled glycans, $60 \mathrm{~cm}$ NCHO-coated capillary columns (Beckman Coulter) with 50 $\mu \mathrm{m}$ diameter were used with the ProteomeLab carbohydrate sieving matrix (Beckman Coulter). All injections were accomplished by 1 psi (pounds per square inch) for $10 \mathrm{~s}$ and the separation voltage was $30 \mathrm{kV}$.

Data were analyzed using paired and unpaired $t$ tests in GraphPad Prism ( $p<0.05$ was considered statistically significant).

Multivariate exploratory analysis. Because the number of patients was 13, the number of features describing patients was 22 , and the number of probe sets was 28,869 , structure hidden in the data could be recovered only by multivariate methods.

Principal components analysis (PCA). This method reduces the dimensionality of the data so that the smallest number of artificial and uncorrelated dimensions and principal components explains as much variation as possi$\mathrm{ble}^{12}$. The success of variance compression is data-dependent and is measured 
Table 1B. Patient measures in responders and nonresponders.

\begin{tabular}{lccc}
\hline Characteristic & Total, mean \pm SD & Responders (range) & Nonresponders (range) \\
\hline Response at Week 14, $\mathrm{n}$ & 13 & 9 & 4 \\
Gender, F/M & $9 / 4$ & $8 / 1$ & $1 / 3$ \\
Age, yrs & $47.31 \pm 8.81$ & $48.2(37-60)$ & $45.2(35-53)$ \\
Duration of disease, mo & $150.46 \pm 130.13$ & $141.3(24-480)$ & $171(48-300)$ \\
Smoking (Brinkman index) & $58.85 \pm 121.01$ & 0 & $191.2(0-375)$ \\
DAS28 at baseline & $5.42 \pm 0.72$ & $5.25(4.36-6)$ & $5.81(4.62-7)$ \\
Week 4 & $3.66 \pm 1.4$ & $3.68(2.39-6)$ & $3.62(1.21-6.21)$ \\
Week 14 & $2.79 \pm 1.41$ & $2.27(0.16-3.82)$ & $3.97(2.72-5.82)$ \\
HAQ at baseline & $1.74 \pm 0.66$ & $1.83(1-2.75)$ & $1.53(0.75-1.875)$ \\
Week 4 & $1.55 \pm 0.65$ & $1.48(0.5-2.62)$ & $1.71(1.25-2.25)$ \\
Week 14 & $1.12 \pm 0.66$ & $0.93(0.12-2)$ & $0.56(1.25-1.87)$ \\
CRP at baseline & $27.9 \pm 47.17$ & $13.8(0.4-40.2)$ & $59.6(2.34-178)$ \\
Week 4 & $19.47 \pm 44.67$ & $4.62(0.5-22.81)$ & $52.89(0.5-161.81)$ \\
Week 14 & $16.83 \pm 37.6$ & $2.89(0.5-16.7)$ & $48.21(0.5-129.56)$ \\
ESR at baseline & $32.08 \pm 22.96$ & $28.4(8-50)$ & $40.2(10-90)$ \\
Week 4 & $15.38 \pm 20.87$ & $9.22(2-28)$ & $29.25(2-76)$ \\
Week 14 & $14.46 \pm 21.3$ & $5.77(1-18)$ & $34(8-80)$ \\
Previous DMARD & $3.46 \pm 1.27$ & $3.33(2-5)$ & $3.75(2-6)$ \\
MTX dose, mg/wk & $14.04 \pm 4.39$ & $14.44(7.5-20)$ & $13.13(10-20)$ \\
Prednisone use, mg/wk & $1.23 \pm 2.52$ & $0.89(0-8)$ & $2(0-4)$ \\
\hline
\end{tabular}

ACR: American College of Rheumatology criteria; R: responder, NR: nonresponder, Brinkman index: no. cigarettes smoked per day $\times$ smoking years, calculated by summing separate Brinkman indices in 3 age periods; DAS28: Disease Activity Score; HAQ: Health Assessment Questionnaire; CRP: C-reactive protein; ESR: erythrocyte sedimentation rate; DMARD: disease-modifying antirheumatic drug; MTX: methotrexate.

by the relative percentages pertaining to each component. Often, $2-3$ components explain $60 \%-70 \%$ of variation, allowing graphic display of results by biplot, which is a simultaneous arrangement of study objects and original variables for a given pair of components. The role of variables in influencing data structure can be evaluated on the basis of length and directionality of arrows pointing to variable positions. These are obtained after arbitrary rescaling of component correlations to allow for effective visualization.

Canonical variates analysis. Whereas PCA recovers underlying structures in the data without any a priori grouping of objects, separation between predefined groups of objects is best revealed by CVA. CVA was used to determine whether the groups of responders and nonresponders are separable in the multidimensional space spanned by the genetic variables, and if so, which gene subsets have the best discriminatory power. The results of CVA are the so-called canonical scores obtained from the canonical functions derived through eigenanalysis, which serve as coordinates of observations in the canonical space.

Since the maximum number of canonical axes is 1 less than the number of groups, in our study CVA did not allow graphic display, and separation of responders and nonresponders is expressed merely by a list of scores for observations on a single canonical axis. If the observations are taken at random and the variables satisfy multivariate normality, then statistical procedures are available to test the significance of group separation. Nevertheless, if these criteria are not met, as in our case, examination of the 2 groups as to whether they overlap on the canonical axis or not provides equally meaningful information. A partial limitation of CVA is that the number of variables cannot exceed the number of observations (patients). Therefore, many CVA runs were carried out using different subsets of genes, each subset defined on a logical basis. As a control, we used several sets of genes selected randomly from a set of genes known to have no influence on group separation.

Computations were performed using the Syn-Tax 2000 package $^{13}$.

\section{RESULTS}

Clinical characteristics. We used a binary outcome variable to assess clinical responder status: patients with ACR0 or ACR20 scores were classified as nonresponders (Patients 1,2, $12,13)$; and patients with ACR50 or ACR70 scores were classified as responders (Patients 3 to 11 ). Within 4 and 14 weeks of tocilizumab therapy, disease activity of all patients decreased significantly when all patients were considered as a single group (Table 1A and $1 \mathrm{~B}$ ).

Figure 1A shows distribution of the patient population according to a combination of ACR categories, DAS28 improvement between baseline and Week 14 when responder status was assessed, and DAS28 at Week 14. PCA of clinical measures can also differentiate between groups of responders and nonresponders although there is a clear transition zone, and results were most influenced by 2 patients (Figure 1B; Appendix, Supplementary Figure 1). These suggest that the clinical characteristics of the patient groups do not allow clear differentiation between various stages of responsiveness to therapy. ELISA analyses of serum from this group of patients did not reveal significant differences in IL-6 or IL-8 serum cytokine levels (Appendix, Supplementary Figure 2), therefore these data were not used for further analyses (levels of IL-1ß could not be detected).

Global gene expression analyses and validation. Microarray analysis of all samples at baseline and Week $4(n=26)$ revealed 59 genes that showed significant differences between baseline and Week 4 after correction for multiple testing. The list of genes and their functional categories, such as response to external stimulus, immune system process or regulation of Personal non-commercial use only. The Journal of Rheumatology Copyright () 2012. All rights reserved. 
Table 2A. Significant differences in gene expression between baseline and Week 4 .

\begin{tabular}{lllllr}
\hline $\begin{array}{l}\text { Transcript } \\
\text { Cluster ID }\end{array}$ & Gene & Symbol & Localization & p & $\begin{array}{r}\text { Functional Category } \\
\text { Associations } \\
\text { (PMID) }\end{array}$ \\
\hline
\end{tabular}

Arachidonate 12-lipoxygenase

8170119 Four and a half LIM domains 1

7945262 Junctional adhesion molecule 3

8041383 Latent transforming growth factor beta binding protein 1

8016832

7900683

8157650

7919984

8126269

8173135

8115397

8051583

8112274

8050240

8149927

8060745

8018864

8101762

8123744

8007931

8090162

8100966

8100971

7922200

8136067

7982597

8111772

8096845

8176174

8145736

7954293

8102532

8169617

7991602

8115327

8109093

7924996

8118249

7973403

7942204

8078650

8145005

7904361

8117034

8016044

8166723

8118235

8103695

8096415

8062312

8145766

7944876

8089015

8071268

8057797

8120833

7948900

8156706

8063716

Monocyte to macrophage differentiation-associated

Myeloproliferative leukemia virus oncogene

Prostaglandin-endoperoxide synthase 1

Selenium binding protein 1

Triggering receptor expressed on myeloid cells-like 1

Aminolevulinate. delta-. synthase 2

Chromosome 5 open reading frame 4

Cytochrome P450. family 1. subfamily B. polypeptide 1

ELOVL family member 7

Ornithine decarboxylase 1

Clusterin

Spermine oxidase

Suppressor of cytokine signaling 3

Synuclein. alpha

Coagulation factor XIII. A1 polypeptide

Integrin. beta 3

Integrin. beta 5

Platelet factor 4 - CXCL4

Chemokine (C-X-C motif) ligand 7

Selectin P

Tetraspanin 33

Thrombospondin 1

Disabled homolog 2

Epidermal growth factor (beta-urogastrone)

Membrane protein. palmitoylated $1.55 \mathrm{kDa}$

Neuregulin 1

Phosphodiesterase 3A. cGMP-inhibited

Phosphodiesterase 5A. cGMP-specific

Progesterone receptor membrane component 1

Proprotein convertase subtilisin/kexin type 6

Secreted protein. acidic. cysteine-rich (osteonectin)

Actin-binding LIM protein 3

Chromosome 1 open reading frame 198

Chromosome 6 open reading frame 25

CKLF-like MARVEL transmembrane domain containing 5

Cortactin

Carboxy-terminal domain. RNA polymerase II

Erythrocyte membrane protein band 4.9 (dematin)

Family with sequence similarity 46 . member C

Guanosine monophosphate reductase

Integrin. alpha $2 \mathrm{~b}$

Kell blood group precursor (McLeod phenotype)

Lymphocyte antigen 6 complex. locus G6D

Microfibrillar-associated protein 3-like

Multimerin 1

Myosin. light polypeptide 9. regulatory

Neuregulin 1

Neurogranin (protein kinase C substrate. RC3)

Protein S (alpha)

Septin 5

Serum deprivation response

$\mathrm{SH} 3$ domain binding glutamic acid-rich protein like 2

Small nucleolar RNA. C/D box 30

Tropomodulin 1

Tubulin. beta 1

$\begin{array}{ccccc}\text { ALOX12 } & 17 \mathrm{p} 13.1 & 0.011 & \text { Immune system process } & \\ \text { FHL1 } & \mathrm{Xq} 26 & 0.023 & \text { Immune system process } & \\ \text { JAM3 } & 11 \mathrm{q} 25 & 0.028 & \text { Immune system process } & 18821692 \\ \text { LTBP1 } & 2 \mathrm{p} 22-\mathrm{p} 21 & 0.011 & \text { Immune system process } & 17594488\end{array}$

$\begin{array}{llll}M M D & 17 \mathrm{q} & 0.011 & \text { Immune system process }\end{array}$

$\begin{array}{llll}M P L & 1 \mathrm{p} 34 & 0.011 & \text { Immune system process }\end{array}$

PTGS1 9q32-q33.3 $0.016 \quad$ Immune system process

SELENBP1 1q21-q22 $0.019 \quad$ Immune system process

TREML1 6p21.1 $0.011 \quad$ Immune system process

ALAS2 Xp11.21 $0.016 \quad$ Lipid metabolic process

C5orf4 5q31-q32 $0.023 \quad$ Lipid metabolic process

$\begin{array}{llll}C Y P 1 B 1 & 2 \mathrm{p} 21 & 0.019 & \text { Lipid metabolic process }\end{array}$

$\begin{array}{llll}\text { ELOVL7 } & 5 \mathrm{q} 12.1 & 0.023 & \text { Lipid metabolic process }\end{array}$

$\begin{array}{llll}O D C 1 & 2 \mathrm{p} 25 & 0.023 & \text { Lipid metabolic process }\end{array}$

$\begin{array}{llll}C L U & 8 \mathrm{p} 21-\mathrm{p} 12 \quad 0.013 \quad \text { Regulation of apoptosis }\end{array}$

$\begin{array}{llll}\underline{S M O X} & 20 \mathrm{p} 13 & 0.011 & \text { Regulation of apoptosis }\end{array}$

$\underline{S O C S 3} \quad 17 q 25.3 \quad 0.013 \quad$ Regulation of apoptosis

$\begin{array}{llll}S N C A & 4 \mathrm{q} 21 & 0.009 & \text { Regulation of apoptosis }\end{array}$

F13A1 6p25.3-p24.3 0.009 Response to external stimulus

$\begin{array}{llll}\text { ITGB3 } & 17 \mathrm{q} 21.32 & 0.011 & \text { Response to external stimulus }\end{array}$

$\begin{array}{llll}\text { ITGB5 } & 3 \mathrm{q} 21.2 & 0.016 & \text { Response to external stimulus }\end{array}$

$\begin{array}{llll}P F 4 & 4 \mathrm{q} 12-\mathrm{q} 21 & 0.028 & \text { Response to external stimulus }\end{array}$

$\begin{array}{llll}P P B P & 4 \mathrm{q} 12-\mathrm{q} 13 & 0.023 & \text { Response to external stimulus }\end{array}$

$\begin{array}{llll}S E L P & 1 \mathrm{q} 22-\mathrm{q} 25 & 0.009 & \text { Response to external stimulus }\end{array}$

$\begin{array}{llll}\text { TSPAN33 } & 7 \mathrm{q} 32.1 & 0.013 & \text { Response to external stimulus }\end{array}$

$\underline{\text { THBS1 }} \quad 15 \mathrm{q} 15 \quad 0.016$ Response to external stimulus

$\begin{array}{llll}D A B 2 & 5 \mathrm{p} 13 & 0.023 & \text { Signal transduction }\end{array}$

$\underline{E G F} \quad 4 \mathrm{q} 25 \quad 0.016 \quad$ Signal transduction

$\overline{M P P 1} \quad \mathrm{Xq} 28 \quad 0.023 \quad$ Signal transduction

NRG1 8p21-p12 $0.019 \quad$ Signal transduction

$\begin{array}{llll}P D E 3 A & 12 \mathrm{p} 12 & 0.028 & \text { Signal transduction }\end{array}$

PDE5A 4q25-q27 $0.023 \quad$ Signal transduction

PGRMC1 Xq22-q24 $0.028 \quad$ Signal transduction

$\begin{array}{llll}P C S K 6 & 15 \mathrm{q} 26.3 & 0.005 & \text { Signal transduction }\end{array}$

$\begin{array}{llll}\text { SPARC } & 5 \mathrm{q} 31.3-\mathrm{q} 32 & 0.009 & \text { Signal transduction }\end{array}$

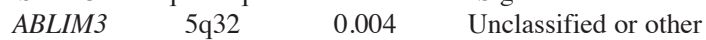

$\begin{array}{lll}C 1 \text { orf198 } & 1 \mathrm{q} 42.2 \quad 0.003 \quad \text { Unclassified or other }\end{array}$

$\begin{array}{llll}\text { C6orf25 } & 6 \mathrm{p} 21.31 & 0.013 \quad \text { Unclassified or other }\end{array}$

CMTM5 14q11.2 $0.023 \quad$ Unclassified or other

$\begin{array}{llll}C T T N & 11 \mathrm{q} 13 & 0.009 & \text { Unclassified or other }\end{array}$

CTDSPL 3p21.3 $0.011 \quad$ Unclassified or other

$\begin{array}{llll}E P B 49 & 8 \mathrm{p} 21.1 & 0.009 & \text { Unclassified or other }\end{array}$

FAM46C $\quad 1 \mathrm{p} 12 \quad 0.006 \quad$ Unclassified or other

$\begin{array}{llll}G M P R & 6 \mathrm{p} 23 & 0.003 & \text { Unclassified or other }\end{array}$

ITGA2B $\quad 17 \mathrm{q} 21.32 \quad 0.007 \quad$ Unclassified or other

$\begin{array}{llll}X K & \mathrm{Xp} 21.1 & 0.005 & \text { Unclassified or other }\end{array}$

LY6G6D 6p21.3 $0.028 \quad$ Unclassified or other

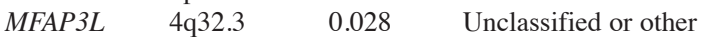

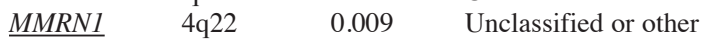

$\begin{array}{lll}\text { MYL9 } & 20 \mathrm{q} 11.23 \quad 0.002 \quad \text { Unclassified or other }\end{array}$

$\begin{array}{llll}M S T 131 & 8 \mathrm{p} 12 & 0.023 & \text { Unclassified or other }\end{array}$

$\begin{array}{llll}N R G N & 11 \mathrm{q} 24 & 0.013 & \text { Unclassified or other }\end{array}$

$\underline{P R O S 1} \quad 3 \mathrm{p} 11-\mathrm{q} 11.2 \quad 0.016 \quad$ Unclassified or other

SEPT5

Unclassified or other

SDPR 2q32-q33 $0.011 \quad$ Unclassified or other

SH3BGRL2 6q13-15 $0.019 \quad$ Unclassified or other

SNORD30 11q13 $0.013 \quad$ Unclassified or other

$\begin{array}{llll}\text { TMOD1 } & 9 \mathrm{q} 22.3 & 0.011 \quad \text { Unclassified or other }\end{array}$

$\begin{array}{llll}T U B B 1 & 20 \mathrm{q} 13.32 & 0.009 & \text { Unclassified or other }\end{array}$

16269423

17056579

18820827

15345499

2672272

19485899

19680656

15660456

$\mathrm{p}$ value after correction; functional categories that genes were assigned to and whether they are associated with rheumatoid arthritis are shown. Underlined genes play a role in IL-6 signaling according to the Direct Interaction Pathway Analysis of Genespring GX10. PMID: PubMed (US National Library of Medicine) ID.

Personal non-commercial use only. The Journal of Rheumatology Copyright (c) 2012. All rights reserved. 
Table $2 B$. Pearson correlations ( $\mathrm{r}$ ) and $\mathrm{p}$ values of genes used in correlation analyses. Numbers in bold type represent significant correlations.

\begin{tabular}{lcccc}
\hline & \multicolumn{2}{c}{ Baseline } & \multicolumn{2}{c}{ Week 4} \\
& $\mathrm{p}$ & $\mathrm{r}$ & $\mathrm{p}$ & $\mathrm{r}$ \\
\hline DAS28 and gene expression & & & & \\
ALAS2 & $\mathbf{0 . 0 0 0 1}$ & 0.78 & 0.42 & 0.05 \\
DDX4 & $\mathbf{0 . 0 0 0 1}$ & 0.75 & 0.29 & 0.09 \\
DYRK3 & $\mathbf{0 . 0 0 0 1}$ & 0.75 & 0.84 & 0.003 \\
EPB42 & $\mathbf{0 . 0 0 0 2}$ & 0.74 & 0.59 & 0.02 \\
GMPR & $\mathbf{0 . 0 0 1}$ & 0.64 & 0.25 & 0.11 \\
ITGB3 & 0.35 & 0.07 & $\mathbf{0 . 0 4}$ & 0.32 \\
PTX3 & $\mathbf{0 . 0 0 0 1}$ & 0.75 & 0.87 & 0.002 \\
RGL1 & $\mathbf{0 . 0 0 0 1}$ & 0.77 & $\mathbf{0 . 0 5}$ & 0.29 \\
RUNDC3A & $\mathbf{0 . 0 0 0 1}$ & 0.74 & 0.61 & 0.02 \\
SLC25A39 & $\mathbf{0 . 0 0 0 1}$ & 0.76 & 0.47 & 0.04 \\
TMEM56 & $\mathbf{0 . 0 0 0 2}$ & 0.74 & 0.08 & 0.24 \\
TMOD1 & $\mathbf{0 . 0 0 0 1}$ & 0.75 & 0.28 & 0.1 \\
DAS28 (Week 14) and gene expression (baseline) & & \\
MAP7D1 & $\mathbf{0 . 0 0 0 3}$ & 0.7 & & \\
PDAP1 & $\mathbf{0 . 0 0 0 2}$ & 0.73 & & \\
ZIC3 & $\mathbf{0 . 0 0 0 1}$ & 0.8 & & \\
\hline
\end{tabular}

DAS28: Disease Activity Score. apoptosis, and their relation to IL-6 signal pathways is shown in Table 2A.

We then examined gene expression differences determining clinical response. Microarray analysis of samples at baseline $(n=13)$ identified 787 probe sets showing significant differences between responders $(n=9)$ and nonresponders $(n=$ 4). As the female/male ratio is $1 / 3$ in the group of nonresponders, we sought to remove the differences caused by the disequilibrium in gender-specific gene expression; therefore probe sets differentiating between men and women and responders and nonresponders were compared, resulting in a list of 686 probe sets devoid of gender differences (Figure 2A). Expression changes of 4 genes, CCDC32, DHFR, EPHA4, and TRAV8-3, remained statistically significant after correction for multiple testing. Future analyses should confirm if these genes can be used as predictors of the clinical outcome.

Next, as our study was based on an exploratory approach, we used a technical validation, RT-QPCR, to determine the expression levels of 12 genes (4 genes from the nonresponders vs responders; and 8 genes from the baseline vs Week 4 comparisons) for each sample $(n=26)$. In 10 out of 12 genes
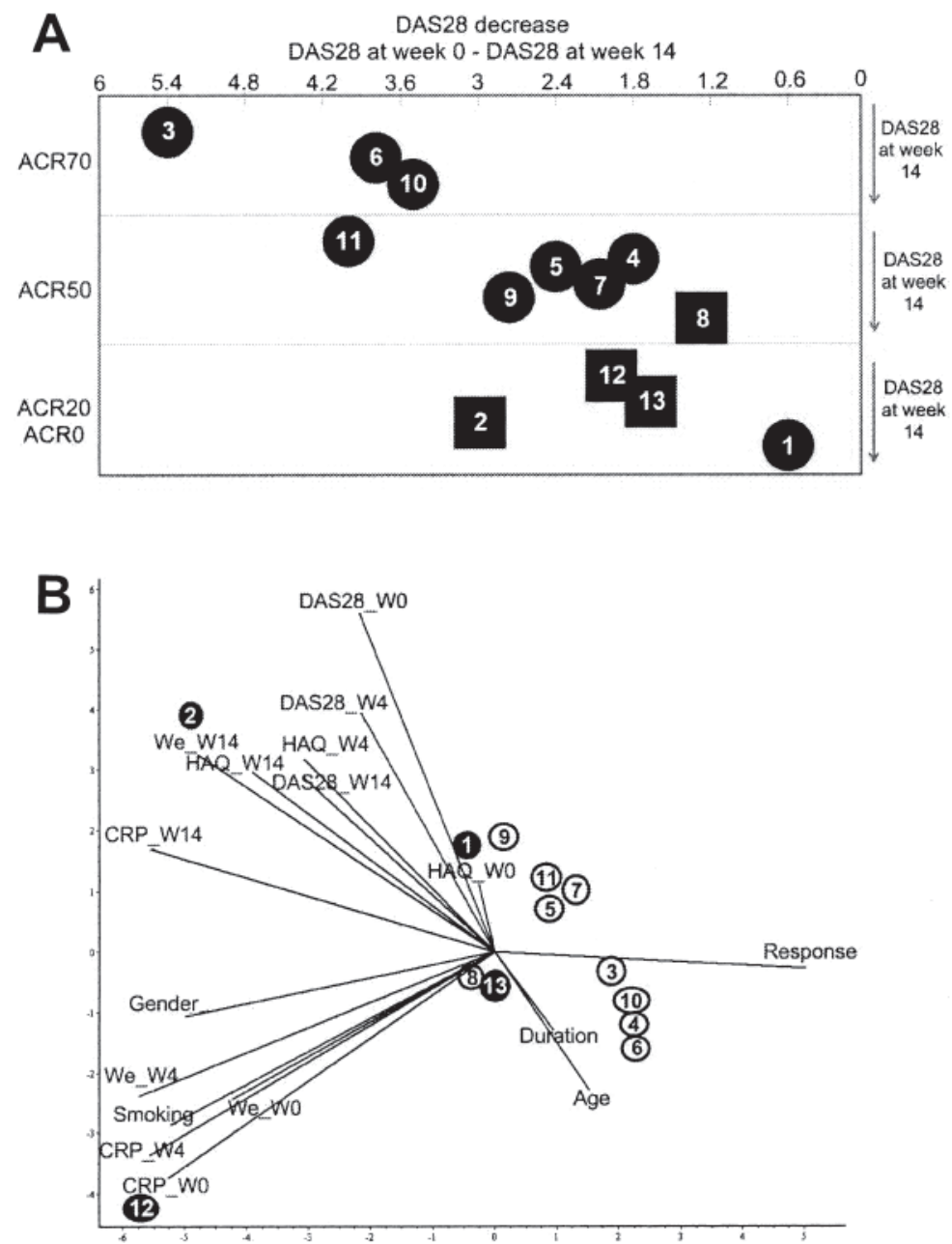

Figure 1. Clinical assessment of patients by ACR criteria; DAS28 improvement and PCA analysis. A. Circles and squares indicate female and male patients, respectively. Numbers represent individual patients based on assessment included in Table 1. Patients are classified by ACR criteria (ACR0-20 to ACR70, $\mathrm{y}$-axis from bottom to top); by DAS28 improvement between baseline and Week 14 (0-6, x-axis, from right to left); and by DAS28 value at Week 14 (at right, lowest to highest values, from top to bottom in each horizontal section). B. Principal component analysis (PCA) was performed on data from all patients as 1 group using measures such as responder status, age, gender, smoking status, duration of disease, DAS28, erythrocyte sedimentation rate (ESR), C-reactive protein (CRP), and Health Assessment Questionnaire (HAQ) at Week 0, 4, and 14. Black circles represent nonresponders.

Personal non-commercial use only. The Journal of Rheumatology Copyright @ 2012 . All rights reserved. 

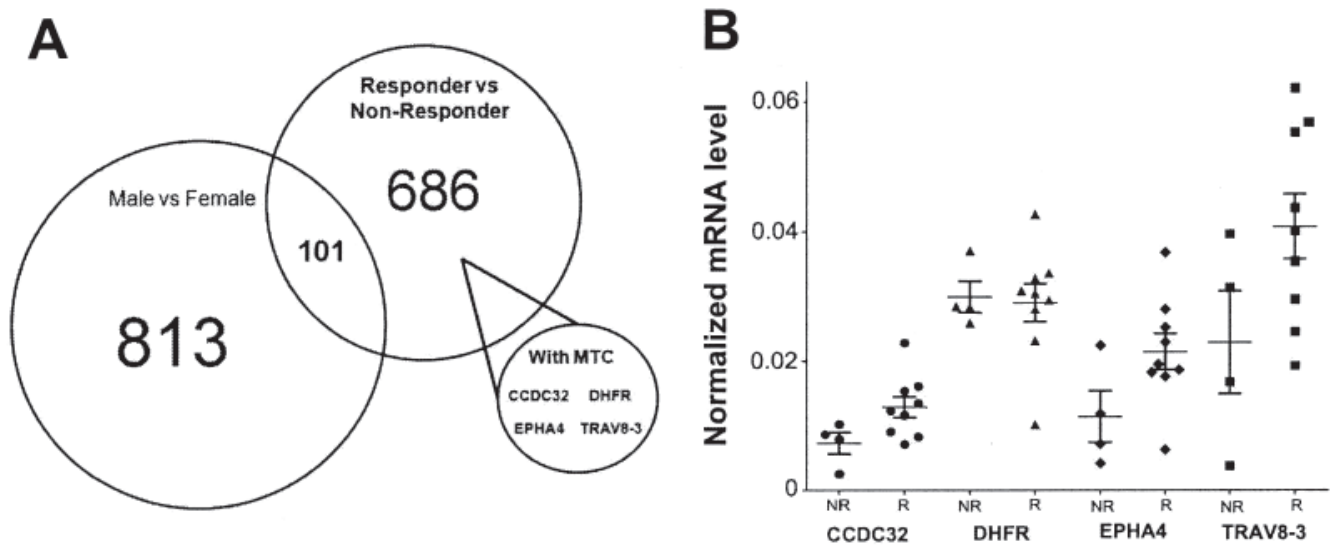

\begin{abstract}
Figure 2. Gene expression differences between responders and nonresponders. A. Gene expression differences based on microarray experiments between responders and nonresponders. Gender-specific gene expression differences were subtracted, leading to a list of 686 probe sets differentiating between responder statuses without differences caused by gender. Changes in 4 genes, CCDC32, DHFR, EPHA4, and TRAV8-3, remained statistically significant after correction for multiple testing (Benjamini-Hochberg). B. Normalized mRNA levels of genes CCDC32, DHFR, EPHA4, and TRAV8-3 (with $\mathrm{SD}$ ) showing significant differences between responders and nonresponders were validated by RT-QPCR measurements. Normalized mRNA levels of the indicated genes for each patient are shown.
\end{abstract}

selected (CCDC32, EPHA4, and TRAV8-3 between nonresponders and responders; ALAS2, CLU, GMPR, ITGB3, ITGA2B, SH3BGRL2, and TREML1 between baseline and Week 4), the normalized mRNA levels showed significant differences validating the microarray data (Figure 2B; Appendix, Supplementary Figure 3).

Correlation with clinical measures. We also sought to merge the gene expression data with clinical measures such as DAS28. Gene expression levels of 9 genes, ALAS2, DYRK3, EPB42, PTX3, RGL1, RUNDC3A, SLC25A39, TMOD1, and TMEM56, at baseline showed significant correlation with DAS28 scores at baseline ( $\mathrm{r}>0.74, \mathrm{p} \leq 0.0002)$. In addition, $R G L 1$ showed significant correlation after treatment since the gene expression level and DAS28 at Week 4 correlated $(\mathrm{r}=$ $0.29, \mathrm{p}=0.05)$. ITGB3 was the only gene that showed correlation between gene expression and DAS28 at Week 4 after failing to correlate with DAS28 at baseline $(r=0.32, p=$ 0.04). Gene expression levels at baseline of 3 genes (MP7DI, $P D A P 1$, and ZIC3) showed significant correlation with DAS28 scores at Week 14 ( $\mathrm{r}>0.70, \mathrm{p} \leq 0.0003$; Table 2B).

Canonical variates analysis. Univariate statistics may be used to compare expression levels gene by gene, disregarding potential interactions between them. It is often the case, however, that while individual genes cannot separate the 2 groups of patients, the same genes used simultaneously do provide perfect segregation in the multidimensional space (with genes as axes and patients as points). Therefore, we wanted to identify groups of genes that can potentially be used as best discriminators between the 2 groups of patients. Using CVA, we were able to detect a set of genes with the highest discriminatory power.

Nine gene lists were selected for CVA (Figure 3). A list containing IL-6 pathway-related genes (column 4); and 4 lists obtained from the set of genes showing significant differences between responders and nonresponders, such as a list containing genes with the lowest corrected $\mathrm{p}$ value; a list containing genes with the highest fold change; a randomly generated list from this comparison; and the 4 genes whose changes remained significant after correction for multiple testing showed sufficient discrimination between responders and nonresponders (columns 1, 2, 3, 5). Gene sets derived from this study (columns 1-3, Figure 3) showed remarkable discriminatory power, especially the set (column 1) containing genes with the most statistically significant changes. Gene lists compiled by other authors ${ }^{13}$, such as PBMC studies in infliximab treatment for RA (column 6) and genes related to synovium, showed moderate separation (column 7), while lists generated by the highest $\mathrm{p}$ values or randomly selected genes served as negative controls (columns 8 and 9, Figure 3; and Appendix, Supplementary Table 1).

Degree of galactosylation of $\operatorname{Ig} G \mathrm{~N}$-glycans increases after treatment and in responders versus nonresponders. As the expression levels of the B4GALT1 gene encoding the beta 1,4-galactosyltransferase enzyme that plays a critical role in the glycosylation of $\operatorname{IgG}^{14}$ showed significant differences between responders and nonresponders without correction for multiple testing, we turned our attention to other genes coding for enzymes related to this process, such as $\alpha 1$,6-fucosyltransferase (FUT8) and B1,4-N-acetylglucosaminyltransferase III (MGAT3) and found clear differences regarding the responder status (Appendix, Supplementary Figure 4). Thus we measured the degree of galactosylation of the N-glycans of IgG. We analyzed and compared the glycosylation patterns in RA samples to reveal a potential correlation between IgG1 N-glycan profile, galactosyl transferase expression, and the pathogenesis of RA (Figure 4).

Personal non-commercial use only. The Journal of Rheumatology Copyright () 2012. All rights reserved. 


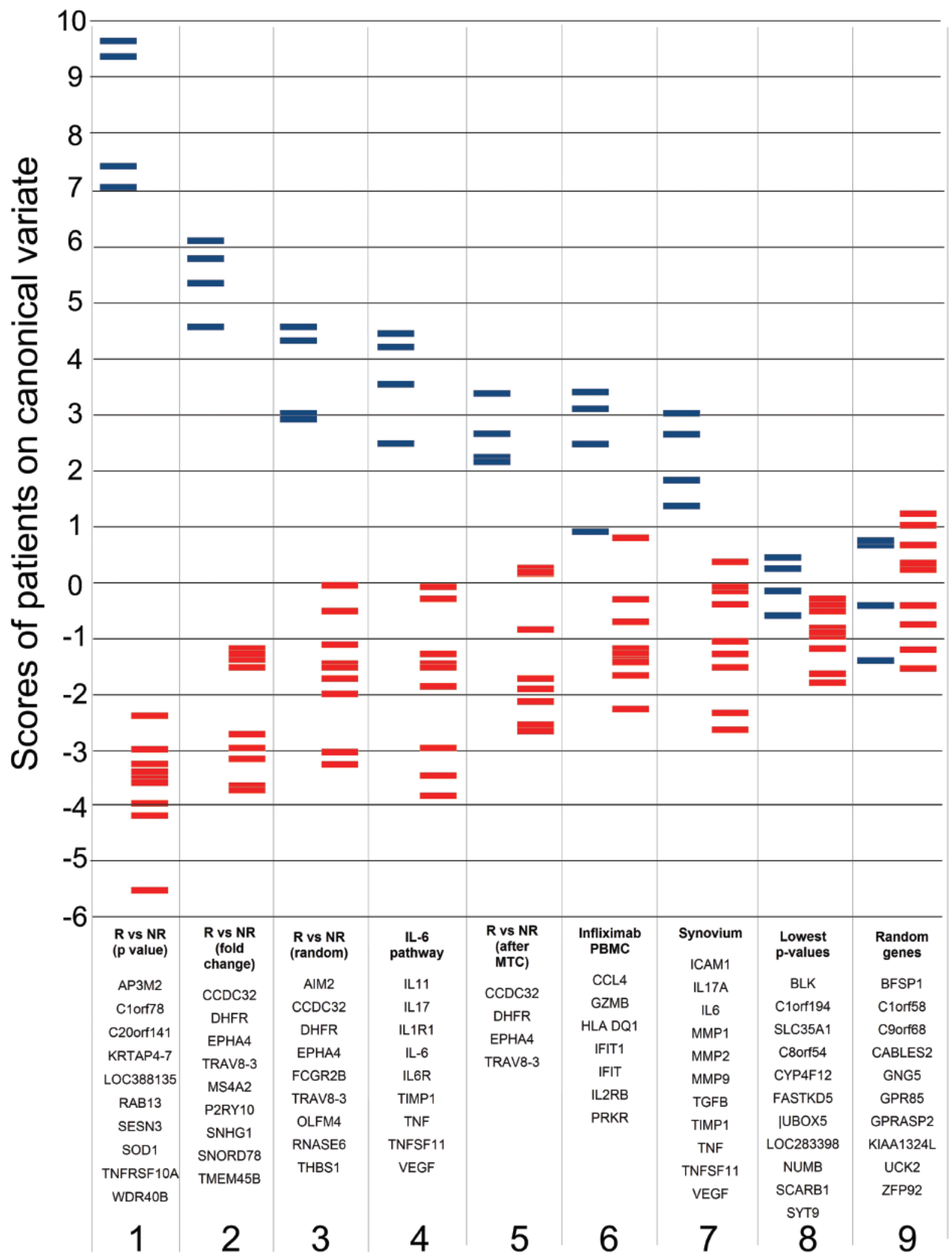

Figure 3. Nine gene lists were evaluated by canonical variates analysis. The power of canonical correlation decreases from left to right. Red bars represent responders, blue bars represent nonresponders. The bigger the space between the groups and the less the overlap among samples, the higher the power of separation of the gene list.

$$
\text { Personal non-commercial use only. The Journal of Rheumatology Copyright @ }{ }^{2012 . ~ A l l ~ r i g h t s ~ r e s e r v e d . ~}
$$


The percentage of the area under the curve of IgG G0 is lower in the group of responders compared to that of nonresponders at baseline (Figure 4A) and after treatment (Figure 4B). Comparing the ratio of $\mathrm{IgG} \mathrm{G0}$ and $\mathrm{G} 1+\mathrm{G} 1{ }^{\prime}+\mathrm{G} 2$, which is the ratio of agalactosylated and galactosylated $\mathrm{IgG}$ glycans, there was a decrease in responders compared to nonresponders at baseline and after treatment (Appendix, Supplementary Figure 5A and 5B).

Regarding the comparison of all baseline samples and the treated ones, IgG G0 area\% (Figure 4C) and the $\mathrm{G} 0 /(\mathrm{G} 1+\mathrm{G} 1$ ' $+\mathrm{G} 2)$ ratio (Appendix, Supplementary Figure 5C) showed a decrease after treatment compared to the baseline values, and this decrease was statistically significant in the case of IgG G0 area\%. These data mean that the degree of galactosylation increases in responding patients, and this shows no correlation with expression changes of the mRNA levels of enzymes in PBMC.
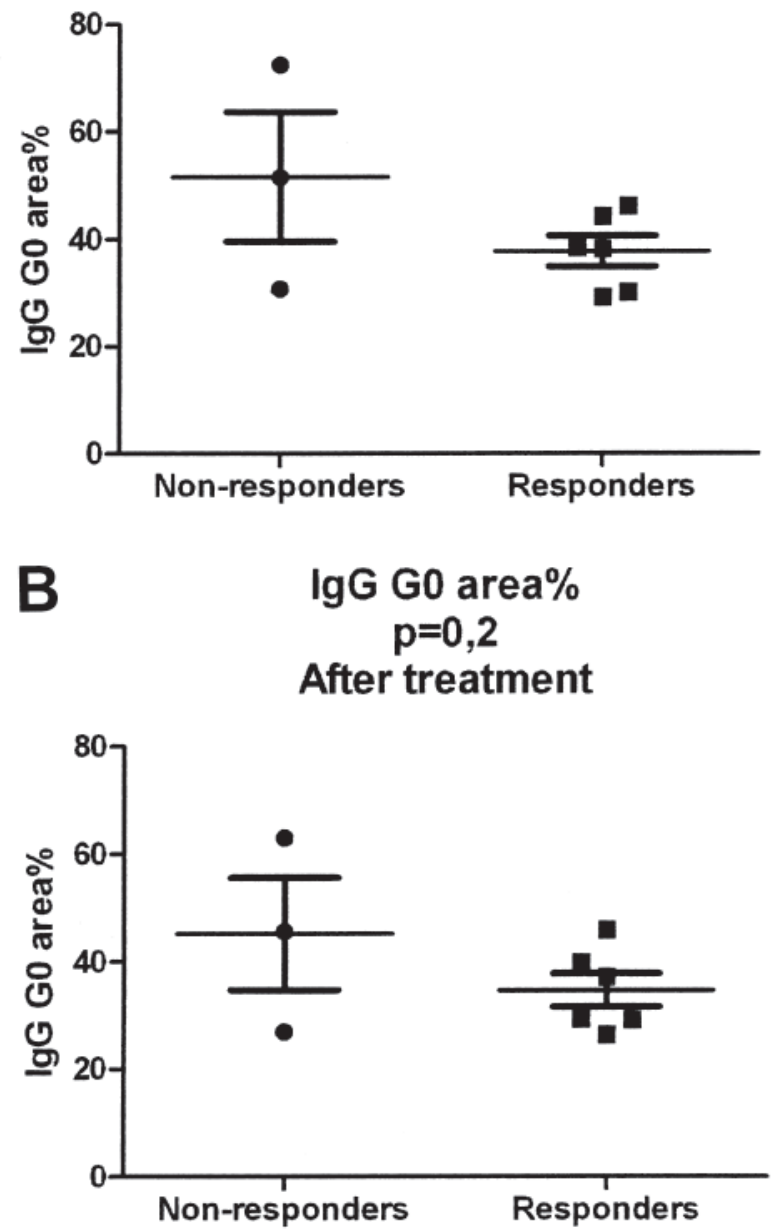

C

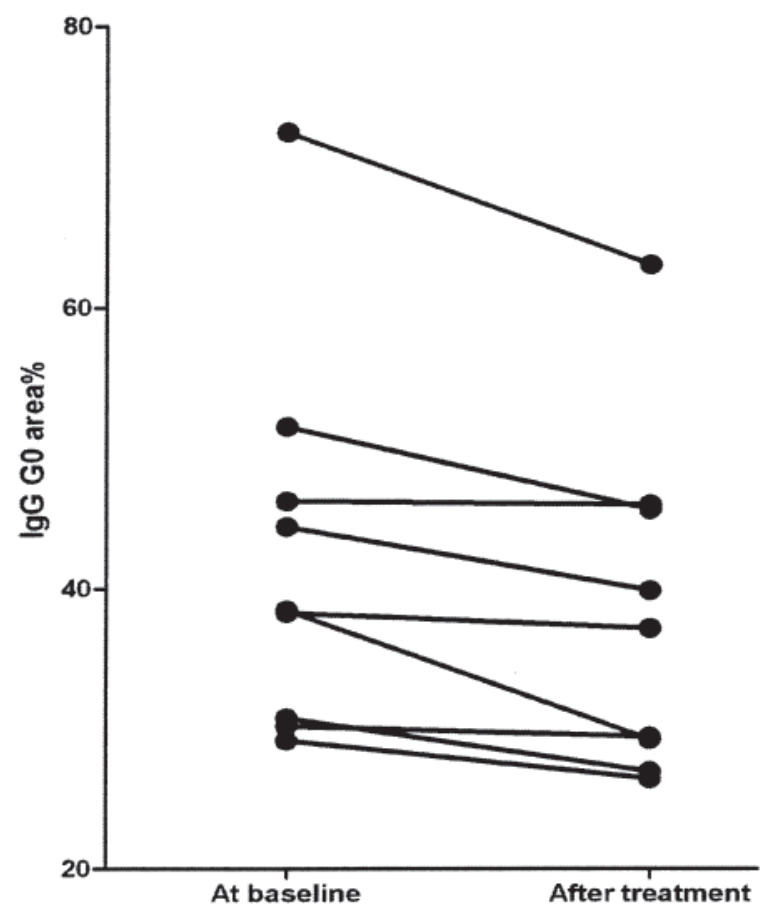

Figure 4. Measuring the degree of galactosylation of N-glycans of IgG. A. Percentage of area under the curve (AUC) of IgG G0 at baseline shows a decrease in responders compared to nonresponders. B. Percentage of AUC of IgG G0 after treatment at Week 4 shows a decrease in responders compared to nonresponders. C. Percentage of AUC of IgG G0 at baseline shows a significant decrease in samples obtained after treatment at Week 4 compared to those obtained at baseline. Matching samples from the same patients are connected to each other between baseline and after treatment. 
only rational scenario for the identification of clinically relevant pathways, gene sets, and predictor markers.

The effects of tocilizumab resulted in changes in the expression of 59 genes between baseline and Week 4, many of them associated with RA, such as $C L U$ (clusterin), coding for a secreted protein with multiple activities related to inflammation, immunity and a regulatory activity on complement; EGF; ITGB3 (integrin beta 3); JAM3; LTBP1; PF4; PTGS1 (prostaglandin-endoperoxide synthase 1 ), which has a widely recognized role in inflammation; SOCS3; SPARC; and THBS1. That these genes showed significant differences between baseline and second infusion of infliximab underlines how important inflammation-related pathways are in the contribution to the effects of therapy.

Regarding the 4 genes that determined responder status at baseline, single nucleotide polymorphism (SNP) of DHFR (dihydrofolate reductase) was identified as a putative predictor for MTX response, efficacy, and side effects in $\mathrm{RA}^{16}$, which suggests that tocilizumab response is related to MTX response. TRAV8-3 (T cell receptor alpha variable 8-3) was mentioned in relation to $\mathrm{CD} 8+\mathrm{T}$ cell response against an HIV-1 epitope ${ }^{17}$; EPHA4 (ephrin receptor A4) plays a role in the nervous system; while the functionality of $C C D C 32$ is unknown.

From genes showing correlation with disease activity and which might explain the effects of tocilizumab, PTX3 (pentraxin 3) was associated with RA and is expressed in response to IL- $1 \beta$ and TNF- $\alpha$, but not to IL-6 in synovial tissue ${ }^{18}$. The other 3 genes (MAP7D1, PDAP1, and ZIC3) showing correlation between baseline gene expression and Week 14 DAS28 might be considered as potential markers of response since at baseline they predicted disease activity at Week 14 (time of determining remission).

Evidence indicating an important link between glycosylation changes and autoimmune rheumatic disease has been presented $^{10}$. The effect of infliximab biologic therapy on the galactosylation of $\mathrm{N}$-glycans of $\operatorname{IgG}$ has also been shown ${ }^{11}$. Attention has been focusing on the interrelationship between reduced galactosylation of the oligosaccharides of $\mathrm{IgG}$, autosensitization, which is thought to be of central importance in the pathogenesis of RA, and the enzyme B1,4-galactosyltransferase that catalyzes the addition of galactose to the oligosaccharide chains on $\mathrm{IgG}^{14}$. We showed that the normalized mRNA levels of the gene encoding this enzyme differentiate in a statistically significant way between responders and nonresponders at baseline to tocilizumab therapy, and the degree of galactosylation of the N-glycans of IgG increases significantly after treatment, in responders versus nonresponders. The change in galactosylation corroborates a previous report ${ }^{14}$ and goes further by showing that it can be used to determine responder status.

In conclusion, the combination of peripheral blood gene expression analyses, clinical scores, and IgG galactosylation can be used to predict clinical response to tocilizumab thera- py in RA. Fifty-nine genes showed significant differences between baseline and Week 4 and thus correlated with treatment. Significantly, 4 genes determined responders after correction for multiple testing. Ten of the 12 genes with the most significant changes were validated using RT-QPCR.

Our data also suggest that CVA is a powerful and widely applicable mathematical tool to identify gene sets with the highest discriminatory power. We had access to only a relatively small patient group $(n=13)$, which remains a limitation of our study; therefore these results need further validation on independent, larger sample sets.

The normalized mRNA values of B4GALT1 encoding B1,4-galactosyltransferase, which catalyzes the addition of galactose to human $\operatorname{IgG}$, differentiates between responders and nonresponders at baseline in a statistically significant way, and the degree of galactosylation of the N-glycans of IgG increases significantly after treatment.

To our knowledge, this is the first examination of gene expression changes resulting from tocilizumab therapy in RA; gene sets discriminating between responders and nonresponders were found and validated; and a significant increase in the degree of galactosylation of N-glycans of IgG was documented; however, these results have to be tested in larger independent cohorts.

\section{ACKNOWLEDGMENT}

We thank Ibolya Fürtos for help in processing samples; Prof. Sandor Sipka for the ELISA experiment and analysis; and Emese Petoné for help with sample collection. Microarray analysis was carried out by the Microarray Core of the Debrecen Clinical Genomics Center.

\section{REFERENCES}

1. Tracey D, Klareskog L, Sasso EH, Salfeld JG, Tak PP. Tumor necrosis factor antagonist mechanisms of action: A comprehensive review. Pharmacol Ther 2008;117:244-79.

2. Dayer JM, Choy E. Therapeutic targets in rheumatoid arthritis: The interleukin-6 receptor. Rheumatology 2010;49:15-24.

3. Suzuki M, Hashizume M, Yoshida H, Mihara M. Anti-inflammatory mechanism of tocilizumab, a humanized anti-IL-6R antibody: Effect on the expression of chemokine and adhesion molecule. Rheumatol Int 2010;30:309-15.

4. Oldfield V, Dhillon S, Plosker GL. Tocilizumab: A review of its use in the management of rheumatoid arthritis. Drugs 2009;69:609-32.

5. Nishimoto N, Yoshizaki K, Miyasaka N, Yamamoto K, Kawai S, Takeuchi T, et al. Treatment of rheumatoid arthritis with humanized anti-interleukin-6 receptor antibody: A multicenter, double-blind, placebo-controlled trial. Arthritis Rheum 2004;50:1761-9.

6. Smolen JS, Beaulieu A, Rubbert-Roth A, Ramos-Remus C, Rovensky J, Alecock E, et al. Effect of interleukin-6 receptor inhibition with tocilizumab in patients with rheumatoid arthritis (OPTION study): A double-blind, placebo-controlled, randomised trial. Lancet 2008;371:987-97.

7. Mesko B, Poliska S, Szegedi A, Szekanecz Z, Palatka K, Papp M, et al. Peripheral blood gene expression patterns discriminate among chronic inflammatory diseases and healthy controls and identify novel targets. BMC Med Genomics 2010;3:15.

8. van Baarsen LG, Wijbrandts CA, Timmer TC, van der Pouw Kraan TC, Tak PP, Verweij CL. Synovial tissue heterogeneity in rheumatoid arthritis in relation to disease activity and biomarkers in peripheral blood. Arthritis Rheum 2010;62:1602-7. 
Supplementary Table 1. Canonical correlation, chi-square, and Wilks' lambda values of gene lists used for canonical variates analysis (Figure 3). The higher the canonical correlation and chi-square, and the lower the Wilks' lambda, the stronger the gene list.

\begin{tabular}{lccc}
\hline List & $\begin{array}{c}\text { Canonical } \\
\text { Correlation }\end{array}$ & Chi-square & $\begin{array}{c}\text { Wilks' } \\
\text { Lambda }\end{array}$ \\
\hline R vs NR (p) & 0.99 & 21.83 & 0.02 \\
R vs NR (fold change) & 0.97 & 18.33 & 0.05 \\
R vs NR (random) & 0.94 & 13.74 & 0.12 \\
IL-6 pathway & 0.94 & 13.68 & 0.12 \\
R vs NR (after MTX) & 0.88 & 13.70 & 0.22 \\
Infliximab PBMC & 0.88 & 11.14 & 0.23 \\
Synovium & 0.86 & 7.22 & 0.27 \\
Lowest p & 0.193 & 0.23 & 0.96 \\
Random genes & 0.014 & 0 & 0.99 \\
\hline
\end{tabular}

R: responder; NR: nonresponder; IL-6 interleukin 6; MTX: methotrexate; PBMC: peripheral blood mononuclear cells.

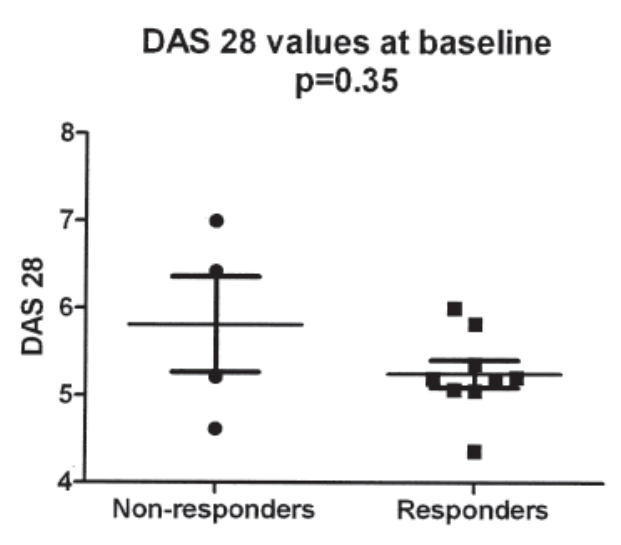

DAS 28 values at week 4 $\mathrm{p}=0.93$

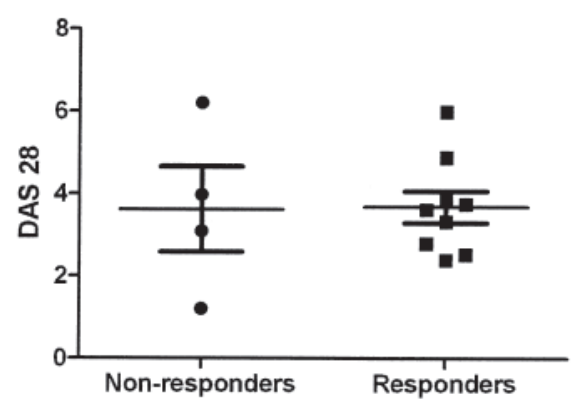

Supplementary Figure 1. Disease Activity Score 28 joint (DAS28) values at baseline and at Week 4 for comparison of responders and nonresponders.
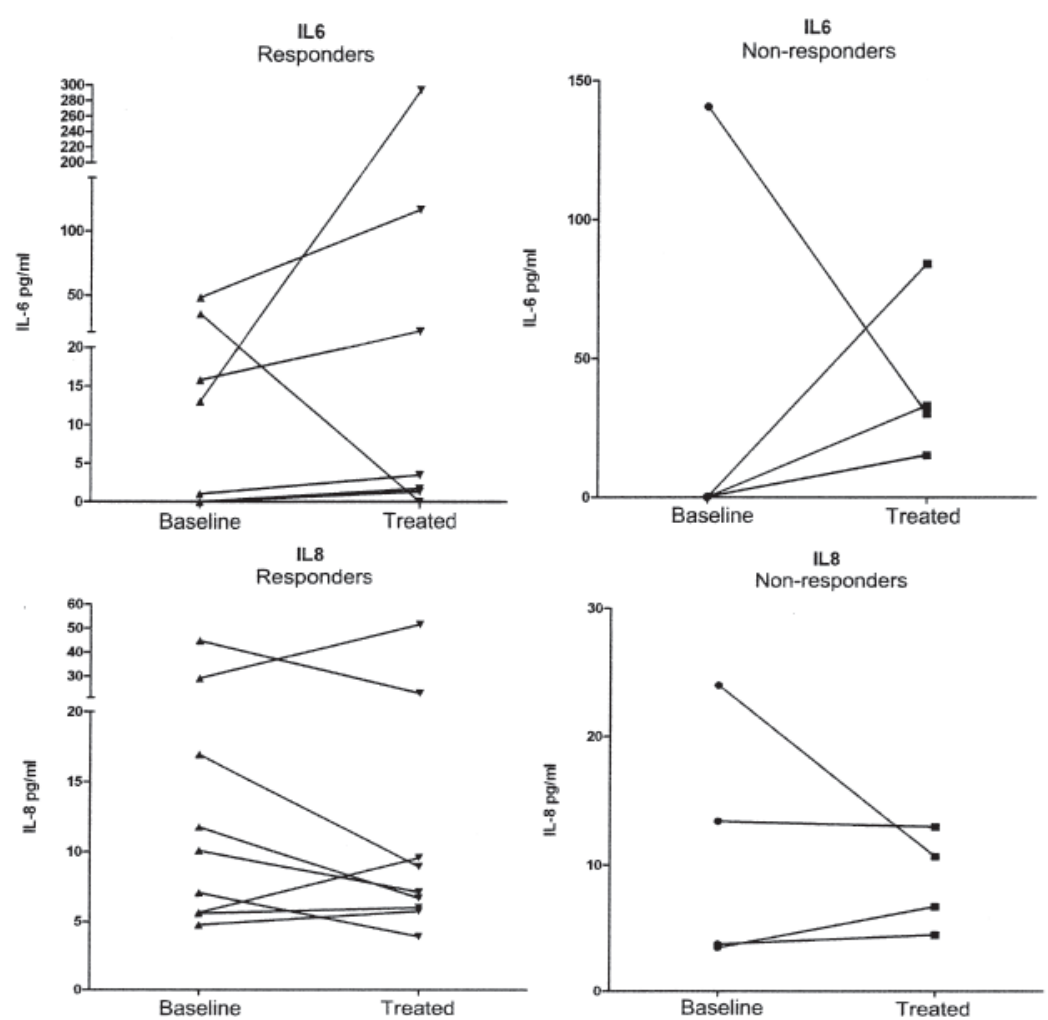

Supplementary Figure 2. Serum cytokine levels of interleukin 6 (IL-6), IL-1ß, and IL-8 were measured by ELISA from samples obtained from all patients at baseline and Week 4. Cytokine levels of IL-6 and IL-8 showed no significant change in responders versus nonresponder, or samples at baseline versus at Week 4. Cytokine levels of IL-1ß were below measurement limit.

9. van 't Veer LJ, Dai H, van de Vijver MJ, Wesseling J, Nuyten DS, van Krimpen C, et al. Gene expression profiling predicts clinical outcome of breast cancer. Nature 2002;415:530-6.

10. Axford JS, Sumar N, Alavi A, Isenberg DA, Young A, Bodman KB, et al. Changes in normal glycosylation mechanisms in autoimmune rheumatic disease. J Clin Invest 1992;89:1021-31.
11. Croce A, Firuzi O, Altieri F, Eufemi M, Agostino R, Priori R, et al. Effect of infliximab on the glycosylation of $\mathrm{IgG}$ of patients with rheumatoid arthritis. J Clin Lab Anal 2007;21:303-14.

12. Podani J. Introduction to the exploration of multivariate biological data. Leiden: Backhuys; 2000.

13. Podani J. Syn-Tax 2000 computer programs for data analysis in 


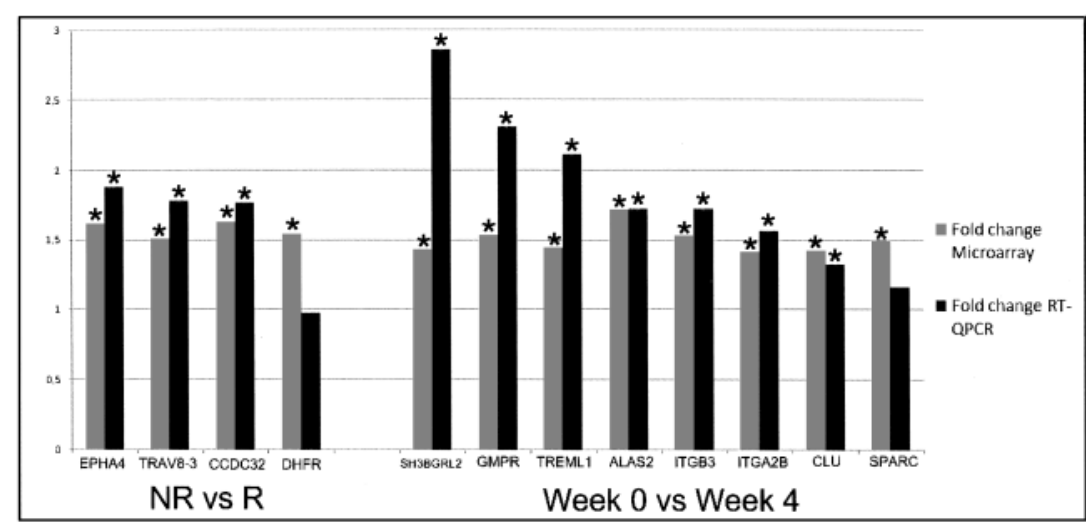

B4GALT1
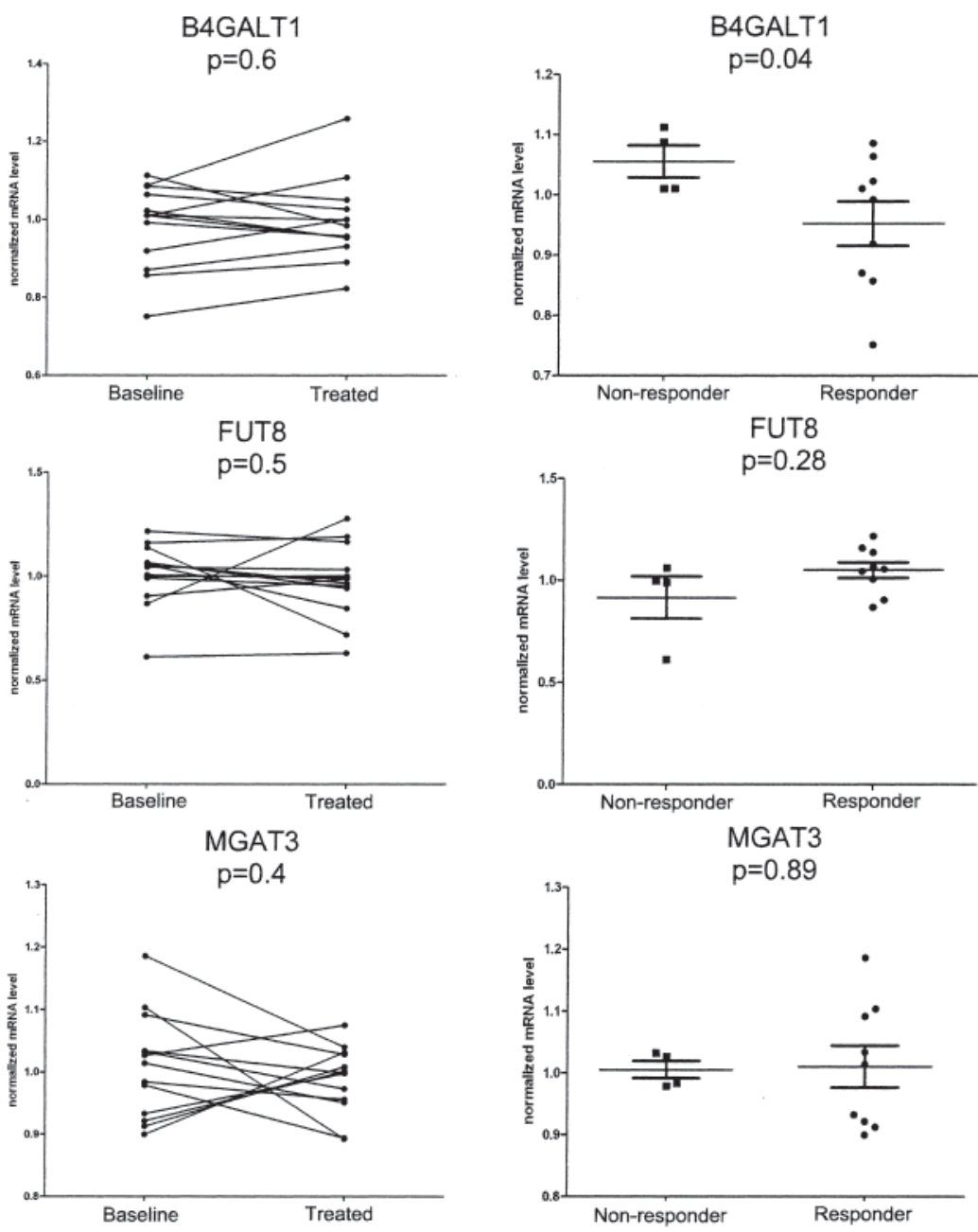

Supplementary Figure 4. Normalized mRNA values of genes coding for enzymes that play a role in the galactosylation of the N-glycans of IgG. Left column shows baseline versus treated comparisons for all 3 genes; right column shows responder versus nonresponder comparisons in all 3 genes.
Supplementary Figure 3. Fold change between responders and nonresponders (first 4 sets of bars); baseline and Week 4 (second 8 sets of bars) by microarray experiments (grey bars) and RT-QPCR (black bars). *Statistically significant comparison (only gene expression changes of DHFR and SPARC by RT-QPCR were not significant)

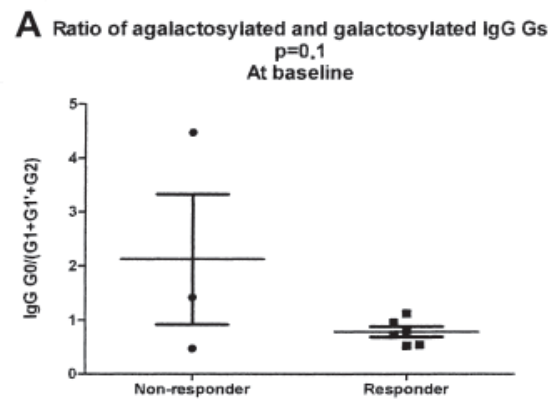

B Ratio of agalactosylated and galactosylated IgG Gs

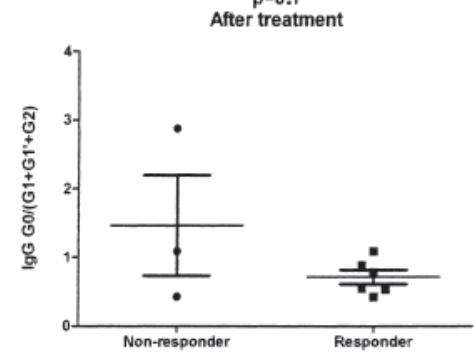

\section{Ratio of agalactosylated and galactosylated lgG Gs $\mathrm{p}=0.1$}

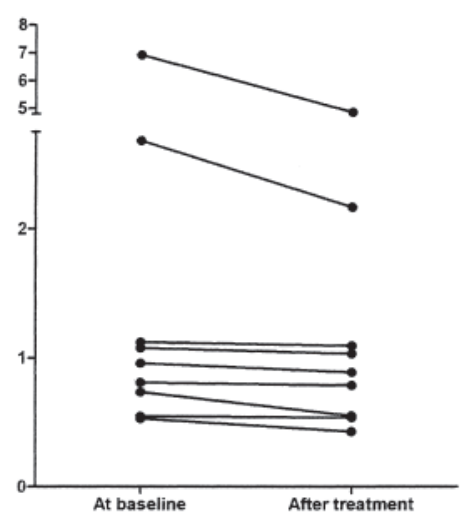

Supplementary Figure 5. A. Ratio of $\operatorname{IgG}$ G0 and $\mathrm{G} 1+\mathrm{G} 1$ ' $+\mathrm{G} 2$, the ratio of agalactosylated and galactosylated IgG glycans at baseline, shows a decrease in responders compared to nonresponders. B. Ratio of $\mathrm{IgG}$ G0 and $\mathrm{G} 1+\mathrm{G} 1{ }^{\prime}+\mathrm{G} 2$, the ratio of agalactosylated and galactosylated IgG glycans after treatment at Week 4, shows a decrease in responders compared to nonresponders. C. Ratio of $\operatorname{IgG~G0}$ and $\mathrm{G} 1+\mathrm{G} 1{ }^{\prime}+\mathrm{G} 2$, the ratio of agalactosylated and galactosylated $\mathrm{IgG}$ glycans after treatment at Week 4 , shows a decrease in samples obtained after treatment at Week 4 compared to those obtained at baseline. Matching samples from the same patients are connected to each other between baseline and after treatment. 
ecology and systematics. User's manual. Budapest: Scientia; 2001.

13a. Sekiguchi N, Kawauchi S, Furuya T, Inaba N, Matsuda K, Ando S, et al. Messenger ribonucleic acid expression profile in peripheral blood cells from RA patients following treatment with an anti-TNF-a monoclonal antibody, infliximab. Rheumatology 2008; $47: 780-8$.

14. Alavi A, Axford J. Evaluation of beta 1,4-galactosyltransferase in rheumatoid arthritis and its role in the glycosylation network associated with this disease. Glycoconj J 1995;12:206-10.

15. Braun-Moscovici Y, Markovits D, Rozin A, Toledano K, Nahir AM, Balbir-Gurman A. Anti-tumor necrosis factor therapy: 6 year experience of a single center in northern Israel and possible impact of health policy on results. Isr Med Assoc J 2008;10:277-81.
16. Sharma S, Das M, Kumar A, Marwaha V, Shankar S, Singh P, et al. Purine biosynthetic pathway genes and methotrexate response in rheumatoid arthritis patients among north Indians. Pharmacogenet Genomics 2009;19:823-8.

17. Miyazaki E, Kawana-Tachikawa A, Tomizawa M, Nunoya J, Odawara T, Fujii T, et al. Highly restricted T-cell receptor repertoire in the CD8+ T-cell response against an HIV-1 epitope with a stereotypic amino acid substitution. AIDS 2009;23:651-60.

18. Luchetti MM, Piccinini G, Mantovani A, Peri G, Matteucci C, Pomponio G, et al. Expression and production of the long pentraxin PTX3 in rheumatoid arthritis (RA). Clin Exp Immunol 2000;119:196-202. 